\title{
Los desposeídos, de Ursula K. Le Guin: ¿una utopía?'
}

\section{(TheDispossessed, byUrsulaK. Le Guin: A Utopia?)}

\section{Silvia Castro Méndez²}

Universidad de Zaragoza, España

\section{resumen}

El estudio se centra en analizar ciertas interrogantes básicas a propósito de la ambigüedad atribuida al títlulo e índole de la obra Los desposeídos, de Ursula K. Le Guin: «una utopía ambigua», ¿utopía o distopía? Se sostiene que la obra es un ejercicio de pensamiento dialéctico, donde el maniqueísmo queda descartado así como la idealización de los sistemas políticos.

\section{abstract}

This study addresses certain basic questions regarding The Dispossessed, de Ursula K. Le Guin, relative to the ambiguity attributed to its title "An Ambiguous Utopia". Is it a utopia or a dystopia? It is posited that it is an exercise of dialectical thinking, where there is no room for Manichaeism or the idealization of political systems.

Palabras clave: litertura utópica, distopía, narrativa estadounidense contemporánea

Keywords: utopian literature, contemporary American literature

La obra literaria de Ursula K. Le Guin (California, 1929) se coloca en el terreno de la ciencia ficción o de la literatura fantástica. Los desposeídos ${ }^{3}$ pertenece a las novelas del primer tipo. Publicada

1 Recibido: 14 de febrero de 2014; aceptado: 6 de junio de 2014.

2 Correo electrónico: scastrom@gmail.com

3 Ursula K. Le Guin, Los desposeídos (Barcelona: Minotauro, 2008). En adelante, las citas de la novela se consignan entre paréntesis. Fue publicado originalmente como The Dispossessed: An

$$
L_{\text {etras }} 55 \text { (2014), ISSN 1409-424X; eISSN 2215-4094 }
$$


en 1974, no tardó en obtener, un año más tarde, los premios Nébula y Hugo, dos galardones a la ciencia ficción en Estados Unidos. Desde entonces, la obra ha adquirido un número creciente de lectores y no pocos se han volcado a la tarea de desentrañar los muy diversos temas que la animan, tanto desde el punto de vista literario como filosófico.

A menudo, se ha considerado que este texto es también parte del género de la literatura utópica. Esta adscripción se basa en el estudio del mundo representado en la novela, es decir, de las características del planeta (o satélite) Anarres, uno de los dos espacios en los que se desarrolla la trama. Más específicamente, se la suele considerar una utopía de índole anarquista, influencia que ha reconocido la autora en varias ocasiones, al igual que la del taoísmo y marxismo ${ }^{4}$.

La autora ha querido incluir Los desposeídos en la categoría utópica, aunque algo la condujo a matizar su adscripción, puesto que agregó un subtítulo. La llamó «una utopía ambigua», aunque años después, la autora eliminó esa clarificación, por razones que comentaremos más adelante.

¿Cuál es la ambigüedad a la que se quiso referir Ursula K. Le Guin? ¿Desde qué puntos de vista puede ser considerada esta obra una utopía y desde cuáles otros puntos de vista habría que delimitar su pertenencia al género? Estas son las preguntas que intentaré responder en el presente artículo; para ello, tendré que concentrarme en aquellos capítulos que se refieren a Anarres.

El personaje principal se llama Shevek, un profesor de física originario de Anarres, que vive en un tiempo futuro. Anarres es un satélite del planeta Urras y el hogar adoptivo de un grupo de individuos que-desde siete generaciones atrás con respecto al momento en que tiene lugar la acción del relato-fueron expulsados de la sociedad

Ambiguous Utopia (Nueva York: Harper \& Row, 1974).

4 Ursula K. Le Guin, «Science Fiction and Mrs. Brown», The Language of the Night: Essays on Fantasy and Science Fiction (Londres: Women's Press, 1989) 101-120. También de la autora, «A Response, by Ansible, from Tau Ceti», The New Utopian Politics of Ursula K. Le Guin's The Dispossessed (Lanham, MD: Lexington Books, 2005) 305-308. 
capitalista de Urras por razones políticas ${ }^{5}$. Por lo demás, Anarres es una sociedad que se funda en las ideas anarquistas de la filósofa Odo, que vivió y murió en Urras antes de la migración. No obstante su origen, Anarres ha desarrollado una serie de vicios que han vuelto rígida su sociedad y la han burocratizado hasta límites bastante opresivos para cualquier espíritu creativo y alternativo. Shevek ha desarrollado en Anarres una nueva teoría del tiempo, que hace prometedor el desarrollo de tecnologías para la transimultaneidad, la transferencia instantánea de la materia.

La teoría también haría posible, de manera más inmediata y evidente, al decir de Shevek, «la comunicación sin lapsos intermedios entre dos puntos del espacio, [...] sin necesidad del intervalo entre el mensaje y la respuesta que es inevitable en el caso de impulsos electromagnéticos» (379, cap. XI). El interés suscitado por estas teorías y los límites insoslayables que encuentran en su luna nativa para dar cabida a la investigación, conducen al protagonista a realizar un viaje insólito a Urras. Lo llamo «insólito», puesto que es la primera vez, desde el viaje fundacional, que un anarresti (o habitante de Anarres) viaja a Urras, desde luego, con la oposición de la mayoría, la curiosidad de algunos y la indiferencia de ninguno.

Una parte del libro transcurre en Urras, donde Shevek descubre, poco a poco, la verdad acerca de esa sociedad que, tras la apariencia de belleza y normalidad, esconde la desigualdad y el autoritaritarismo, a pesar de su riqueza y recursos naturales extraordinarios. Durante su estadía en Urras, Shevek se da cuenta de que los urrasti (habitantes de Urras) están interesados en obtener su teoría -que él mismo nunca llega a desvelar- con fines espurios y de dominación. La identificación de Shevek con los oprimidos de Urras lo hace involucrarse en una revuelta, promovida por su presencia y sus declaraciones de

5 Según la fábula, en 771 fue cedida la Luna a la Sociedad Internacional de Odonianos: «librándose así de ellos a cambio de un mundo, antes de que socavaran irremisiblemente la autoridad de la ley y la soberanía nacional de Urras» (115, cap. IV). Se transportaron en reiterados viajes «el millón de almas que habían elegido una nueva vida» (116, cap. IV). 
corte anarquista. Tras una fortísima represión y el aplastamiento de los rebeldes, Shevek se ve compelido a regresar a su planeta.

La huida se logra gracias a la ayuda de la embajadora de un planeta llamado Terra, quien se compromete a divulgar la teoría física de Shevek para el beneficio del mayor número de seres y mundos. El libro concluye con el viaje de regreso a unaAnarres que, durante la ausenciade Shevek, ha sido reinterpretada y de nuevo abrazada por el físico. Dicho viaje es realizado en compañía de un urrasti llamado Ketho, quien se ha identificado con la promesa de Anarres, pese a todas las incertidumbres acerca del regreso: rechazo colectivo e incluso, muerte.

El libro se articula como contrapunto entre los capítulos dedicados a Urras y Anarres. Los capítulos sobre Anarres constituyen el pasado y los que tratan acerca de Urras, el presente. El primer capítulo y el último corresponden a los viajes hacia Urras y desde Urras, respectivamente.

\section{Elementos utópicos destacados en Los desposeídos}

\section{El viaje (los viajes) y el tiempo}

El viaje es tema central en la literatura utópica, y tal es el caso en Los desposeídos. El viaje supone un distanciamiento radical con la vida y la sociedad, tales como son conocidas en el momento de la escritura de la obra. Es una salida de la cotidianidad y de lo puramente posible en términos convencionales. Dicha ruptura se ve a menudo acompañada por un desplazamiento del tiempo, lo cual contribuye a construir la excepcionalidad de la realidad de la propuesta. En Los desposeídos hay involucrados tres viajes y un futuro distante.

Con respecto a la dimensión temporal, podemos decir que la trama principal se desarrolla, aproximadamente, cien años después de la actualidad. Ese futuro le permite a Le Guin incorporar teorías científicas y desarrollos tecnológicos desconocidos en nuestro tiempo, que incluyen los viajes interplanetarios y con estos, las relaciones de cooperación y el intercambio con habitantes de mundos diferentes. 
En cuanto a los viajes, el primero es fundacional: el viaje en el que un grupo disidente de Urras partió para formar una sociedad distinta y alternativa en el satélite Anarres. Es el punto de partida hacia lo que no existía y un hito cohesionador en el imaginario de Anarres. El segundo viaje es el del regreso al mundo del origen, al mundo de los antepasados al que se renunció colectivamente. Es un viaje al mundo del pasado, no porque sea un viaje en el tiempo, sino porque Urras representa aquella realidad perversa que quedó congelada, estática en el imaginario de los anarresti desde el instante de la migración. El tercer viaje es el del regreso a Anarres. Tal como aparece escrito sobre la tumba de Odo en Urras, es «el verdadero viaje». Este viaje supone la restitución de la promesa de Anarres, la convicción resemantizada, una recuperación dialéctica de la pertenencia de Shevek al destino colectivo de Anarres, con todos los peligros que pueda entrañar.

\section{La insularidad y la metáfora del muro}

El aislamiento es una de las características que se repiten constantemente en la literatura utópica. En palabras de Trousson:

El insularismo utópico es ante todo una actitud mental, de la que la isla clásica no es sino la representación ingenua. Corresponde a la convicción de que sólo una comunidad al abrigo de las influencias disolventes del exterior puede alcanzar la perfección de su desarrollo ${ }^{6}$.

Anarres es un satélite; al decidir su sesgo alternativo durante la colonización, se aspira a dejar de lado, de manera radical, cualquier otra realidad potencialmente contaminante para el desarrollo previsto.

El relato se abre con la descripción de un muro a la vez franqueable e infranqueable; una línea de demarcación precisa y crucial, más que un obstáculo material insuperable. Ambiguo muro, «bifacético» lo llama Le Guin, pues lo es para los de dentro como para los de fuera.

6 Raymond Trousson, Historia de la literatura utópica: viajes a países inexistentes (Barcelona: Península, 1995) 44. 
Este primer muro de la obra encierra las instalaciones que, asociadas al campo de aterrizaje de los viajes entre Anarres y Urras, son el nudo histórico del planeta: la traza física del cordón umbilical de Anarres y su único vínculo actual, siete generaciones después, con lo otro, lo ajeno, lo prohibido, lo negado. Si bien Anarres trata de definirse en positivo, a cada vuelta de la esquina, salta su origen de oposición y termina siendo, a la larga, otredad positiva, que no logra desatarse de su nudo original.

Este muro, además de ser el único muro-frontera en el mundo conocido, es además punto de unión hipotético con otros mundos, en general; esto es, el sitio de arribo de las naves que llegan de otros mundos. Por ende, es además, un territorio de cuarentena, para limpiar lo sucio que acarrea lo ajeno y hacerlo entrar, ya transmutado, digerido, procesado y curado, en una prístina realidad. Desde el punto de vista del universo, el pequeño planeta Anarres, definido como libre frente al otro y salvaguardado tras un muro de raíces genéticas, tiene más resonancias de prisión que de libertad.

\section{Doce excepcionalidades con respecto a «nuestro» mundo}

Existen algunos elementos excepcionales con respecto al mundo que conocemos y conviene mencionar, aunque sea de forma sintética, puesto que la excepcionalidad es una característica muy importante de la literatura utópica:

1. Con el asentamiento en Anarres y el desarrollo de una estructura alternativa en el ámbito político, social, cultural y económico, los nuevos anarresti se dieron a la tarea de crear un nuevo idioma: el právico, una lengua artificial para expresar y representar una realidad de nuevo cuño. Está claro que hay muchas cosas que deben ser expresadas de manera distinta y otro tanto que está completamente vacío de contenido dentro de la nueva realidad creada. 
2. Trousson incluye el desprecio por el dinero como una de las marcas fundamentales de la literatura utópica, pues el sistema monetario engendra desigualdades, jerarquías, injusticias y, por lo tanto, altera el equilibrio y la uniformidad que reclama una sociedad utópica ${ }^{7}$. En Anarres nada se compra ni se vende: se usa, dependiendo de la necesidad. El producto está a golpe de vista: es puro valor de uso.

3. En el libro Democracy in America, Alexis de Tocqueville ${ }^{8}$ sostiene que el interés de los individuos, cuando es bien entendido, se asocia de manera directa con el interés colectivo. Esta idea es la misma que expresa Kropotkin en el capítulo X de Moral Anarquista9. Este es también, uno de los principios que rigen la vida de Anarres. Lo único que puede dar felicidad a los individuos es la capacidad de entrega a los demás. La felicidad de las utopías suele ser una felicidad colectiva, no un gozo individual; por eso, para el utopista hay una especie de horror por el secreto ${ }^{10}$. Esto no es excepción en Anarres, donde el secretismo y las restricciones en el manejo de la información son prácticamente incomprensibles.

4. En Anarres no existe la propiedad privada. Las cosas se obtienen según se necesitan, pero no para su acumulación. Nadie tiene nada que se pueda robar y lo que se necesita simplemente se va a buscar a los almacenes (173, cap. V). Trousson señala el tema del desposeimiento como un rasgo distintivo de las sociedades utópicas: «como nadie posee nada personalmente, los almacenes generales suministran a cada uno lo preciso para sus necesidades. Así el utopista mantiene tanto la igualdad como el reparto justo, liberado del azar y de la

$7 \quad$ Trousson, 44.

8 Alexis de Tocqueville, Democracy in America (Nueva York: Vintage Books, 1945).

9 Piotr Kropotkin. «La moral anarquista». Archivo Kropotkin. Marxist Internet Archive. (2007).

Web. 2011. <http://www.marxists.org/espanol/kropotkin/moral1.htm>.

10 Trousson, 48. 
competencia individualista ${ }^{11}$. Este es un tema crucial en el libro, es precisamente el motivo de su título.

5. La educación en Anarres es considerada un placer, no un camino para el éxito económico ni de otro orden; en ningún caso se piden cuentas de lo aprendido. El interés del estudio nunca se relaciona con la conclusión de niveles, sino con el proceso de adquisición, las preguntas que motiva, la posibilidad de contribuir a la vida colectiva. No hay que olvidar que en la sociedad anarresti la educación suele tener una gran importancia, puesto que es el instrumento de replicación de normas y pensamiento. Es mediante la educación que se alimenta la visión del mundo, la cohesión, la entrega sin reservas al todo, la unanimidad funcional.

6. Los niños suelen permanecer con sus padres biológicos durante los primeros años, pues se considera que el contacto individual es crítico durante esa etapa (145, cap. IV). Pero pasado ese primer estadio de la vida, que los padres deseen conservar a los niños consigo es visto como una desviación posesiva, como un acto de «propietarismo» ${ }^{12}$. Esto porque «la célula familiar constituye fácilmente un núcleo refractario al orden social y hace que se prefieran los intereses particulares a los de la ciudad» ${ }^{13}$. A los intereses de la comunidad, diríamos en este caso. Padre, madre o hermano pueden ser nombres otorgados a varias personas al mismo tiempo (64, cap. II). Sin apellidos, los nombres de los niños son asignados de manera aleatoria por un ordenador (224, cap. VII) y por tanto, no suponen un apego a ninguna clase de tradición familiar.

11 Trousson, 48.

12 Por lo demás, tampoco se supone que los padres tengan que permanecer juntos. No hay ninguna atadura entre las personas más que el deseo y la voluntad. Ya veremos esto adelante.

13 Trousson, 48. 
7. En Anarres la sexualidad es completamente abierta y sin restricciones de ninguna índole. Si bien existen uniones que pretenden ser de por vida, no hay estímulo para ello. Como lo expresan Manuel y Manuel, en su gran obra sobre el pensamiento utópico, una utopía anarquista supondría que «el matrimonio no vincularía a nadie a su pareja durante más tiempo del deseado, pues la reciprocidad reinaría en todas las relaciones ${ }^{14}$. Crecer en un entorno de completa libertad sexual hace que la sexualidad anarresti sea algo completamente natural y que no existan trazas de compulsividad en ella. Incluso, podríamos decir que hay una falta de tensión sexual entre los personajes de la novela. Pero quizás podría ser también que la lógica de la reducción del mundo, de la que hablaremos en el punto número 11, haya calado igualmente en el ámbito de los deseos y de la sexualidad. Esto por estar los sujetos ligados a una forma rigurosa de contención que atañe a lo material, es decir, por hallarse los individuos culturalizados en una ética de la mesura.

8. En Anarres se da por sentada la total igualdad de género. Cualquier actitud sexista, discriminatoria y de subordinación contra las mujeres resulta ajena o inverosímil, tanto como que existan personas dedicadas a la servidumbre. Esta igualdad se revela, a lo largo del libro, en las posiciones sociales ocupadas por las mujeres, como trabajadoras y profesionales, porque nada las sujeta de manera distinta que a los hombres. Como no hay diferencias, jerarquías ni subordinaciones de género, tampoco es necesario de saber el género de una persona; solo es relevante por motivos personales, íntimos si se quiere, pero no profesionales ni sociales.

14 Frank E. Manuel y Fritzie P. Manuel, El pensamiento utópico en el mundo occidental. Tomo III (Madrid: Taurus, 1981) 274. 
9. El trabajo está asociado al placer de realizar una tarea satisfactoria y de ejercerla óptimamente. Por lo tanto, las personas están siempre dispuestas a generar actividad. En el capítulo IX de Moral anarquista, Kropotkin afirma que en una sociedad libre el trabajo es una necesidad personal y que las personas son capaces de inventar muchas cosas en el afán de persuadirse de que hacen algo últil para la colectividad. Eso sí, en ocasiones, hay que ir adonde la solidaridad lo exija en calidad de voluntario: es un imperativo social. Así las cosas, todos colaboran con los trabajos sucios (como se entenderían ciertos oficios en Urras), pero nadie tiene que trabajar en ellos durante mucho tiempo, a menos que le guste (173, cap. V). Resistirse a ejecutar un trabajo es posible, aunque no es visto con buenos ojos por la sociedad.

10. Trousson se refiere al diseño de algunas de las ciudades de las grandes utopías, donde prima la distribución geométrica en nombre de un control perfecto y tota ${ }^{15}$. En Los desposeídos ocurre algo similar, aunque con menos rigor que en las utopías tradicionales (119, cap. IV). Esta necesidad de regularidad en lo físico se traslada también al ámbito de lo social. En Anarres ha desaparecido toda clase de estratificaciones sociales, todos los individuos son rasos, sin distinción, y sus capacidades y destrezas son alabadas únicamente en virtud del servicio que prestan al conjunto de la sociedad.

11. Otro aspecto es la ética de la austeridad. Los desposeídos se desarrolla en un entorno inhóspito extremo, pero ligado a lo seco, desértico, estéril y extraordinariamente escaso. En opinión de Jameson, el experimento de Le Guin se centra en una especie de «reducción del mundo» por la vía de la escasez, en que -eliminada la batalla darwiniana contra los demás por los recursos disponibles-, los seres humanos «se han quedado 
solos consigo mismos para inventar sus propios destinos» ${ }^{16}$. La escasez hace que la convivencia tenga que seguir los derroteros de la solidaridad a ultranza, porque en eso va la supervivencia de todos. Este alegato contra la abundancia y el despilfarro es también una característica de la utopía ${ }^{17}$. El desposeimiento como valor puede ser un resultado mixto de la convicción ética y las tremendas restricciones ambientales. Sabemos que Ursula K. Le Guin está muy interesada por el taoísmo ${ }^{18}$ y pretende que la vida de Anarres responda a una ética similar; contribuye al reforzamiento de tal afán el hecho de que las alternativas a la ética del desposeimiento, el «tener sin poseer», sean prácticamente nulas en una realidad con tantas limitaciones materiales.

12. Como sociedad anarquista, Anarres no posee un Estado regente $^{19}$, aunque sí, un ente organizativo, una red administrativa y organizativa (CPD, Coordinadora de Producción y Distribución). Esta organización coordina sindicatos, federaciones e individuos que llevan a cabo el trabajo productivo. No da órdenes, pero sabe lo que opina la gente, es decir, tiene conocimiento de - por llamarlo de alguna manera- la conciencia social. Estamos ante la cesión de autoridad, que puede convertirse -como ocurre en muchas sociedades utópicas de la literatura- en un verdadero infierno de regimentación y control. En Anarres se asume que la CPD ejerce sus

16 Fredric Jameson, Arqueologías del futuro: el deseo llamado utopía y otras aproximaciones de ciencia ficción (Madrid: Akal, 2009) 324.

17 Trousson, 49.

18 La propia Le Guin propuso una interpretación del Tao, que fue publicada en 1998 y puede ser consultada en: Lao Tse. «Tao te Ching». The Feminine Tao. Early Women Masters. Web. 2011. <http://www.earlywomenmasters.net/tao/index.html>.

19 Durante la revuelta en Urras, Shevek hace un discurso a los sublevados: «En Anarres no tenemos nada más que nuestra libertad. [...] No tenemos leyes excepto el principio único de la ayuda mutua. No tenemos gobierno excepto el principio único de la libre asociación. No tenemos naciones, ni presidentes, ni ministros ni jefes, ni generales, ni patronos, ni banqueros, ni propietarios, ni salarios, ni caridad, ni policía, ni soldados, ni guerras» (333, cap. IX). 
funciones con total libertad. No es una organización que contenga órganos punitivos, puesto que la verdadera censura la ejerce la opinión de la mayoría. No hay pues, ningún tribunal que dicte justicia. Mucho menos existen prisiones y la sola idea de que una instancia carcelaria pudiera existir, crea horror en las mentes de los anarresti (51, cap. II).

\section{Aspectos distópicos en Los desposeídos}

En el sexto capítulo de Los desposeídos se relata una conversación entre Shevek y Bedap, su amigo de infancia. Este último personaje discute la pérdida de libertades instalada en la vida social de Anarres. Bedap arguye que no existe nada más básico, en el pensamiento odoniano, que la noción según la cual, el cambio es libertad, es vida. Con el tiempo, sin embargo, la gran mayoría de los anarresti ha olvidado o elegido deliberadamente pasar por alto tal verdad fundamental. En lugar de arriesgarse a la desaprobación pública al desafiar la sabiduría recibida y las prácticas establecidas, los anarresti se han asentado dentro de jerarquías seguras y confortables. En vez de luchar a favor del pensamiento crítico sobre el desarrollo de la sociedad, han optado por permitir que otros piensen por ellos. Así, la sociedad utópica de Odo ha degenerado en una sociedad rígida y estática, caracterizada por la conformidad y la obediencia.

La primera consecuencia que Bedap deduce de este estado de cosas parece sacada de las páginas de John Stuart Mill, cuando se refiere a la tiranía de la mayoría. De acuerdo con Stuart Mill:

Existe un límite a la legítima intervención de la opinión colectiva en la independencia individual; y encontrar ese límite y mantenerlo contra los abusos, resulta tan indispensable para la buena marcha de los asuntos humanos como la protección contra el despotismo político ${ }^{20}$.

$\overline{20}$ John Stuart Mill, Sobre la libertad (Madrid: Aguilar, 1972) 68. 
La principal víctima de la tiranía de la mayoría es Tirin, un personaje inconformista, que compone e interpreta una obra considerada como antiodoniana por los anarresti. Por causa de ello, Tirin recibe una reprimenda pública y finalmente, es arrancado de la vida pública y conducido al ostracismo, de tal modo que la aparente disensión queda neutralizada y el consenso social, preservado.

Bedap obtiene unasegundaconclusión: se refierea la preocupación, presente en los inicios de Anarres, respecto de los posibles abusos de poder, la creciente burocratización y la rigidez que podría seguir de la institucionalización de la ayuda mutua. Al respecto, dice Bedap:

[...] olvidamos que el deseo de poder es tan fundamental en el ser humano como el impulso a ayudarnos mutuamente y que eso hay que inculcárselo a cada nuevo individuo, en cada nueva generación. ¡Nadie nace odoniano del mismo modo que nadie nace civilizado! Pero lo hemos olvidado. No educamos para la libertad (192-193, cap. VI).

La amnesia colectiva se manifiesta en el cambio sufrido en la educación de Anarres. Originalmente, se incentivaban la creatividad y el pensamiento libre para desarrollar la sociedad y sus instituciones, pero con el tiempo, se comenzaron a repetir las palabras de Odo como si fueran leyes y el sistema se volvió rígido, moralista y autoritario. Al final, lo mismo ocurrió con la sociedad en su conjunto (193, cap. VI). La sociedad terminó convertida en una máquina de repetición controlada por burócratas.

En el cuarto capítulo se relata cómo los colonos se percataron del potencial peligro del centralismo:

[...] no puede haber un sistema nervioso sin por lo menos un ganglio, y preferentemente un cerebro. Tenía que haber un centro. [...] Y desde el comienzo los colonos comprendieron que aquella centralización inevitable era una permanente amenaza, que necesitaba de una permanente vigilancia (117, cap. IV). 
El temor de los colonos ante un eventual resultado de carácter autoritario se había visto confirmado. Es más, la propia historia de la conformación de la estructura mental de Shevek parece representar este proceso de la sociedad entera, descrito por Bedap. Lo común a los primeros capítulos acerca de Anarres (II, IV, VI y VIII) es el proceso de alienación de Shevek con respecto a las exigencias del mundo en el que vive.

Así, ante la demanda del niño Shevek, quien reclama para sí un sitio caliente e iluminado por el sol en la guardería, la respuesta de la encargada es la siguiente: «Nada es tuyo. Es para usar. Es para compartir. Si no quieres compartirlo, no puedes usarlo» (43, cap. II). Más tarde, Shevek crea la aporía de Zenón en una clase de «hablary-escuchar» y es duramente reprendido, puesto que «el lenguaje es una función bidireccional». Por el contrario, la creatividad intelectual de Shevek es entendida como un acto de egotismo por el monitor de la actividad; por lo tanto, como una comprobación de que su nivel de aprendizaje es inferior al del conjunto del grupo (46, cap. II). En ambos casos, Shevek cae en la frustración, pues sus iniciativas de autoafirmación son reprimidas en aras de preservar el statu quo. Resultado de tales experiencias, Shevek se refugia en las matemáticas como una manera de evadirse de la realidad y buscar un espacio de certeza (46-47, cap. II).

Al mismo tiempo, Shevek adopta una moral social rígida. Ejemplo de ello es la discusión entre varios estudiantes de ciencia, que debaten acerca de la sociedad anarresti (cap. II). Tirin plantea una serie de críticas razonables sobre la política exterior de su mundo, en particular, acerca de las restricciones sobre las relaciones con Urras y la ausencia de información actualizada y no propagandística sobre la sociedad contemporánea de Anarres. Ante la crítica de Tirin, Shevek contesta rápida y dogmáticamente con argumentos que niegan el 
pensamiento crítico sobre las propias normas sociales que lo sujetan y que perpetúan su alienación ${ }^{21}$.

Este patrón de racionalización y alienación se repite en Shevek conforme crece. Esto resulta evidente en la relación con Sabul, su supervisor de investigación en el prestigioso Instituto Central de las Ciencias. Sabul ha sabido explotar la desconfianza de los anarresti hacia Urras para ocupar una posición de privilegio en el Instituto, incluso se ha valido de recursos como el plagio de textos urrastis sin traducir. Sabul logra convencer a Shevek respecto de la valía de tal conducta, y lo incluye como coautor en sus publicaciones. Shevek racionaliza estas actuaciones de la siguente manera:

Pero si todo cuanto deseo es hacer el trabajo [...]. Es mi deber, es mi alegría, es la finalidad de mi existencia. El hombre con quien tengo que trabajar es competitivo y dominante; pero si quiero trabajar, tengo que trabajar con él (140, cap. IV).

Atrapado en el sistema, Shevek prefiere ignorar los modos corruptos del poder antes que perder la aspiración primitiva de libertad, tan desprestigiada en Anarres. El sacrificio de Shevek resulta vano, puesto que su esfuerzo intelectual es traicionado y él, expulsado del puesto en el Instituto. Para justificar el despido, Sabul acude a circunstancias ajenas, por completo, al egoísmo de sus motivos:

La naturaleza abstrusa, irrelevante de la investigación que has realizado en estos últimos años. Además de una cierta impresión, [...] de que tanto tus enseñanzas como tu comportamiento revelan un cierto desapego, un celo privado, falta de altruismo (297, cap. VIII).

21 Muchos años después, el propio Shevek (que entonces ha entrado a formar parte de un sindicato como una manera de resistir el excesivo autoritarismo social) se convierte en motor de la iniciativa para visitar Urras. Es entonces, de nuevo, una niña, su hija, la que sufre de manera contundente la desaprobación social y se ve sometida al epíteto de «traidora», a la burla, la condena y el ostracismo (cap. 12). 
En «The Dynamic and Revolutionary Utopia of Ursula K. Le Guin», Laurence Davis analiza esta última circunstancia de Shevek de la siguiente manera: «Having sacrificed his principles in a futile effort to avoid confronting the ultimate source of both his own psychological alienation and Sabul's exploitative power over him [...] Shevek's reward is the loss of his one abiding consolation ${ }^{22}$, a saber la física y la matemática. Al final, todos estos motivos suman para hacer que Shevek emprenda su camino a Urras.

\section{Sobre la ambigüedad de Los desposeídos}

En su artículo «Science Fiction and Mrs. Brown» ${ }^{23}$, Le Guin alude a un conocido personaje, inspiración de Virginia Woolf ${ }^{24}$. Se trata de una pequeña mujer, que la autora conoció durante un viaje en tren; esta figura poseía una personalidad peculiar, indefensa y asertiva al mismo tiempo, tenaz, frágil y heroica. Ella acabó por convertirse en un personaje atractivo y desafiante; Virginia Woolf llamó a esa mujer Mrs. Brown y la transformó en la materia por antonomasia de la cual está hecho un personaje de ficción. Considera que todas las novelas comienzan con un personaje semejante, una Mrs. Brown, sentada con toda su complejidad en el asiento de enfrente, en un carro del transporte público. Debe ser así, puesto que la principal meta de una novela es tratar de capturar un personaje vivo, «a character». De alguna manera, ese personaje le dice al novelista: «atrápame si puedes».

Le Guin se pregunta, en ese esfuerzo de captura, ¿puede Mrs. Brown sentarse en una nave espacial y ser el personaje de una novela? Visto de otro modo, ¿puede realmente el escritor de ciencia ficción

22 Laurence Davis, «The Dynamic and Revolutionary Utopia of Ursula K. Le Guin», Laurence Davis y Peter Stillman (eds.), The New Utopian Politics of Ursula K. Le Guin's The Dispossessed (Lanham, MD: Lexington Books, 2005) 12.

23 Ursula K. Le Guin, «Science Fiction and Mrs. Brown», The Language of the Night: Essays on Fantasy and Science Fiction (Londres: Women's Press, 1989) 101-120.

24 Virginia Woolf, «Mr. Bennet and Mrs. Brown», The Captain's Death Bed and Other Essays (Nueva York: Harcourt Brace Jovanovich, 1978) 94-119. 
componer una novela? Nosotros vamos a preguntar con ella algo que parece estar implícito en su pregunta: ¿puede una utopía ser una novela en el sentido más estricto de la palabra? Ampliarlo al tema de la utopía parece posible, porque Los desposeídos es una obra de ciencia ficción que la autora consideró una utopía (o al menos, así la concibió). En el ensayo citado, Le Guin revalora términos como «utopía» y «ciencia ficción». Basta con recapitular los ejemplos de obras utópicas que utiliza para establecer sus afirmaciones.

Si recordamos a Cioran, la respuesta a la pregunta de Le Guin sería un rotundo no:

Lo que más impresiona en los escritos utópicos es la ausencia de olfato, de instinto psicológico: los personajes son autómatas, ficciones o símbolos, ninguno es verdadero, ninguno sobrepasa su condición de fantoche, de idea perdida en medio de un universo sin referencias. Incluso los niños son irreconocibles ${ }^{25}$.

Para Le Guin, la respuesta inicial también es no, y por razones muy semejantes. En opinión de Le Guin, Mrs. Brown no está en las obras utópicas ni de ciencia ficción, porque la humanidad es una debilidad en el astronauta, al fin y al cabo, una cualidad irrelevante para su misión: como explorador, lo que importa no es lo que él es íntegramente, sino sus actos para ejecutar la trama; son los actos del astronauta los que cuentan ${ }^{26}$. Así, los géneros de la fantasía, ciencia ficción y utopía suelen contener arquetipos, pero no personajes (characters). Según señala Le Guin, En El señor de los anillos, para tener un auténtico personaje, Tolkien habría tenido que fudir

25 E. M. Cioran, Historia y utopía (Barcelona: Tusquets, 2003) 123.

26 En el texto de Virginia Woolf, Mr. Bennet and Mrs Brown dice que ella entiende que las novelas «deal with character» y que «it is to express character -not to preach doctrines, sing songs, or celebrate the glories of the British Empire, that the form of the novels, so clumsy, verbose, and undramatic, so rich, elastic and alive, has been evolved» (Woolf, 101). Todos los grandes novelistas, dice Woolf, en esa misma obra, «have brought us to see whatever they wish us to see through some character. Otherwise, they would not be novelist at all but poets, historians, or pamphleteers» (Woolf, 103). En opinión de Woolf, con la que parece coincidir Le Guin, la literatura utópica no ha concedido suficiente valor al individuo. 
en uno solo a Frodo Baggins, Sam, Gollum, Sméagol y quizás, al mismo Bilbo ${ }^{27}$.

En el origen de Los desposeídos, el personaje estuvo claro al inicio y luego se enturbió. Era un hombre, una persona, un científico con características físicas muy particulares y con una personalidad profundamente atractiva, «as a flame to a moth»: un personaje que era necesario capturar. Al principio, fue el protagonista de un relato corto: un fugitivo de un planeta similar a un campo de prisioneros -un sitio semejante a un Gulag estelar-, que después de algunas peripecias en otro planeta, retorna con tristeza y nobleza ${ }^{28}$. En suma, nada que mereciera la pena conservar, a juicio de Le Guin. Pese a este fracaso, el personaje sobrevivió como tal, adquirió el nombre de Shevek y se reveló como un personaje de Utopía:

There was something so decent about him, he was so intelligent and yet so disarmingly naïve, that he might well come from a better place than this. But where? The better place; no place. But what did I know about Utopia? Scraps of More, fragments of Wells, Hudson, Morris. Nothing. It took me years of reading and pondering and muddling and much assistance from Engels Marx, Godwin, Goldman, Goodman, and above all Shelley and Kropotkin, before I could begin to see where he came from, and could see the landscape about him -and yes, in a way it was a prison camp, but what a difference! -and the other people, the people whom his eyes saw; and the place, the other place, where he was going, and from which I now knew, as he had always known, why he must return ${ }^{29}$.

Para entender el asunto, interesante es la afirmación acerca del origen de Shevek: él provenía de una especie de campo de prisioneros

27 A pesar de todas estas premisas, Le Guin parece encontrar esbozos de Mrs. Brown en algunos personajes de la literatura fantástica: Mrs. Thea Cadence (Synthajoy, de D.G. Compton) y Mr. Nobusuke Tagomi (Man in the High Castle, de Philip K. Dick). Ver Le Guin, «Sience Fiction and Mrs. Brown», 107.

28 Le Guin, «Science Fiction and Mrs. Brown», 111.

29 Le Guin, «Science Fiction and Mrs. Brown», 111-112. 
-distinto del lugar propuesto en el relato desechado, en el que la autora quiso hacer habitar al personaje. Un campo de prisioneros no es lugar para una utopía; sin embargo, Le Guin afirma: «the book that resulted is a Utopia, of sorts». ¿Cómo combinar ambas afirmaciones?, ¿qué tipo de utopía es una cuya residencia se sitúa en una especie de campo de prisioneros?, ¿será más bien una distopía? Algunos críticos han considerado que Los desposeídos no solo es una utopía literaria, sino que aportó una contribución especial al género. Por ejemplo, Burns cita tres tipos de análisis: los que consideran que es una utopía fallida, una utopía de final abierto o una utopía posdistópica ${ }^{30}$. Incluso, podría catalogarse como una utopía crítica, pero utopía al fin ${ }^{31}$.

El aspecto más sugestivo de la novela consiste es desvirtuar la idea de que algo perfecto pueda ser creado como lugar definitivo para la convivencia humana. Así, la obra no es completamente utópica en el sentido convencional: describir una sociedad perfecta yestática, definitiva y rígida en el fin de la historia. Al respecto, la autora aclara:

$[\ldots]$ the book doesn't have a happy ending. It has an open ending. As pointed out in at least one of the chapters, it's quite posible that both Shevek and Ketho will be killed on arrival by an angry mob. And it's only too likely that Shevek's specific plans and hopes for his people will come to little or nothing. That would not surprise Ketho ${ }^{32}$.

Burns insiste en que la obra no es utópica ni distópica, pues tal elección no se presenta en el fondo; piensa en otra alternativa:

$[\ldots]$ a novel which deals with the tension between the utopian and the dystopian impulses, and this is played out in the lives of individual characters who inhabit two different societies which might

30 Tony Burns, Political Theory, Science Fiction and Utopian Literature: Ursula K. Le Guin and The Dispossessed (Maryland: Lexington Books, 2010) 126.

31 «Le Guin's most recent opinions on this subject now reflect the general trend amongst commentators on her work which considers The Dispossessed as representing a significant turning point in the history of the concept of a literary utopia. It is a critical utopia in Moylan's sense» (Burns, 142).

32 Le Guin, «A Response, by Ansible, from Tai Ceti», 308. 
be characterized as being either utopian or dystopian, depending on one's point of view ${ }^{33}$.

Existe la posibilidad de que esta sea la postura ambigua a la que se refiere Le Guin respecto del título original de la novela. La insistencia de Burns adquiere sentido al considerar que la ciencia ficción es una especie de puesta en escena de una tesis específica, donde lo fundamental es la tesis. Esto es muy distinto que de lo que ocurre en una novela, en la que se muestran las tensiones, dilemas, contradicciones y decisiones que existen en la vida de las personas. Las utopías, piensa Burns, son más bien obras didácticas, pobres en caracterización y trama. Para hacer justicia al relato de Le Guin, debemos señalar la presencia, en la novela, de preocupación por la condición humana y los dilemas morales asociados a ella.

En «Science Fiction and Mrs. Brown», Le Guin explica que Los desposeídos es una obra didáctica, satírica e idealista ${ }^{34}$. Además, reflexiona sobre la novela temática, aquella que no logra que la propuesta moral termine siendo aprehendida como resultado de la experiencia vital compartida, sino que explicita su proposición. Para la novelista, el didactismo supone una debilidad, pues convierte al texto en un discurso directivo y no en una obra artística. Casi pueden escucharse las palabras de Cioran:

[...] los inventores de utopías son moralistas que sólo perciben en nosotros desinterés, apetito de sacrifico, olvido de sí. Exangües, perfectos y nulos, azotados por el Bien, desprovistos de pecados y de vicios, sin espesor ni contorno, sin iniciación a la existencia, al arte de avergonzarse de sí mismos, de variar sus vergüenzas y sus suplicios, no sospechan siquiera el placer que nos inspira el abatimiento de nuestros semejantes, la impaciencia con la que anticipamos y seguimos su caída ${ }^{35}$.

33 Burns, 129.

34 Le Guin, 112.

35 Cioran, 123-124. 
Puesto que el triunfo de la novela contradice a una explicitación de la propuesta moral, Le Guin reconoce la presencia de ese «pecado» en su propia obra, ya que con frecuencia, nos dice, se sienten, y se escuchan en sus páginas los engranajes de la máquina utópica. Da la impresión de que al momento de escribir «Science Fiction and Mrs. Brown», en 1976, Le Guin se vio forzada a escoger, cuando en realidad quería decir que el texto era, a la vez, una utopía y una novela. Quiso dar a su obra una doble adscripción (novela y utopía), porque, emocionada por la humanidad del personaje principal, abre la puerta a una nueva forma: «I do believe that there is basically a novel, because at the heart of it you will not find an idea, or an inspirational message, or even a stone axe, but something frailer and obscurer, and more complex: a person» ${ }^{36}$. En suma, Le Guin creía que hay algo de Mrs. Brown en el personaje de Shevek y, aunque estaba sumida en la autocrítica, consideraba que la obra tenía el aliento de una verdadera novela.

Más convencida, en 2005, Le Guin sostuvo que el texto bien podía ser entendido como una novela; a menudo, por tratar el tipo de asuntos que incluye (política, sociedad y ética), muchos han entendido su obra como un tratado y no como una novela y esto, en palabras suyas «has given me a lot of grief». Considera que tal problema fue producto del subtítulo, pues las utopías son generalmente leídas como mapas de teoría o práctica social:

[Los desposeídos] has [...] often been discussed as a treatise, not as a novel. This is my own damn fault, of course - what did it expect, announcing itself as a utopia, even if an ambiguous one? Everybody knows utopias are to be read as novels but as blueprints for social theory or practice ${ }^{37}$.

Aunque la escritora solía leer las utopías como novelas, hizo lo propio al escribirla y creyó que su obra podía ser entendida como

36 Le Guin, «Science Fiction and Mrs. Brown», 112.

37 Le Guin, «A Response, by Ansible, from Tau Ceti», 306 
ambas cosas a la vez. La ambigüedad se convirtió, tres décadas después, en certeza de otro signo. Le Guin no cree que, por apartarse del tono de los panfletos, el texto deje de ser una utopía; de igual manera, el que incluya algunos elementos didácticos no implica que deje de ser novela. Por causa de las confusiones que ha causado, en las nuevas versiones del texto, ella ha desechado el subtítulo original. Vistas así las cosas, ante la pregunta respecto de la relación entre novela, ciencia ficción y utopía, Le Guin responde sí, siempre y cuando el autor sea capaz de capturar a Mrs. Brown en las páginas de la obra.

Al respecto, volvamos a un asunto ya mencionado: la obra de Le Guin trata dilemas, tensiones, contradicciones y decisiones presentes en la vida de las personas, en particular, en la vida de Shevek. En consecuencia, esta obra se ocupa de la condición humana y los dilemas morales; propone una especie de doble juego utópico/distópico a partir de las experiencias vividas por Shevek en dos sociedades distintas.

Le Guin está interesada en un problema señalado por Frank y Fritzie Manuel, en las primeras páginas del estudio titulado El pensamiento utópico en el mundo occidental:

Si en el fondo de toda utopía existe una antiutopía -el mundo real visto a través de los ojos críticos del fabricador de la utopía- también puede decir inversamente que en el fondo de toda distopía late una secreta utopía ${ }^{38}$.

¿Es la intención de Ursula K. Le Guin mostrar la utopía en la distopía (Urras) y la distopía en la utopía (Anarres)? Burns contesta esta pregunta del siguiente modo:

[...] The Dispossessed is a novel the main theme of which is precisely this tension between two different forms of utopian/dystopian thinking and writing, as it is played out in the lives of its individual characters, end especially its central character, Shevek ${ }^{39}$.

38 Manuel y Manuel, 20.

39 Burns, 115. 
En «A Non-Euclidian View of California as a Cold Place to Be», Le Guin asevera: «We are in a rational dilema, and either/or situation as perceived by the binary computer mentality, and neither the either nor the or is a place where people can live ${ }^{40}$. Al respecto, Burns afirma: «This suggests that she considers it to be her task in The Dispossessed to portray a situation where admittedly imaginary (and yet in some important sense nevertheless real or realistic) people could and do live» ${ }^{41}$.

En otras palabras: Los desposeídos corresponde, a cabalidad, con los preceptos formulados por la propia autora, pues ella concibe a la novela como un género en que los personajes funcionan como caracteres complejos. Este texto trata, además, acerca de los dilemas del pensamiento utópico. Le Guin recupera los seres y problemas ordinarios, que sitúa en un mundo imaginario, pero plausible. El resultado es un libro que trasciende una exposición de ideas y logra una auténtica corporalización («the embodiment») de ideas ${ }^{42}$. Según $\mathrm{Stow}^{43}$, Le Guin ejecuta un verdadero experimento mental, semejante a las pruebas científicas. La narradora pretende enseñar a pensar dialécticamente (o motivar a hacerlo) respecto de problemas morales y políticos fundamentales. Según Burns, Le Guin preserva, niega y transforma el modo utópico de escribir:

$[\ldots]$ provided this is taken to mean that the utopian principle, together with its opposite, the dystopian principle, is a component element, or "moment" in the Hegelian sense, of the structure of the novel as a whole. From this point of view, the utopian principle is sublated or aufgehoben within Le Guin's text, which might in consequence be

40 Ursula K. Le Guin, «A Non-Euclidian View of California as a Cold Place to Be», Dancing at the Edge of the World: Thoughts on Words, Women, Places (Londres: Gollancz, 1989) 98.

41 Burns, 116.

42 Le Guin, «A Response, by Ansible, from Tau Ceti», 306.

43 Simon Stow, «Worlds Apart: Ursula K. Le Guin and the Possibility of Method», Laurence Davis y Peter Stillman (eds.), The New Utopian Politics of Ursula K. Le Guin's The Dispossessed (Lanham, MD: Lexington Books, 2005) 37-51. 
thought of as going beyond it, whilst at the same time incorporating its esencial features within itself ${ }^{44}$.

Anarres no es una sociedad perfecta ni ideal; ni siquiera para los propios anarresti. ¿Es mejor que Urras? Mejor sí, si nos apropiamos de la visión particular del anarquismo que está detrás de sus imperfecciones, si la analizamos desde la perspectiva de sus habitantes, incluso de los descontentos. Le Guin hace visibles las costuras de esa sociedad, a la que no beatifica. En particular, evidencia lo difícil que es la vida en un planeta con semejantes barreras ecológicas. Desde el punto de vista de la ecología, vivir en medio de la riqueza ambiental de Urras parece mucho mejor, aunque conviene recordar olvidar que en el planeta cunden la desigualdad e injusticia.

Tanto Urras como Anarres pueden ser descritos como «satélite del otro» (cap. IV), depende del sitio desde el que se mire. No impera entonces, un punto de vista absoluto, sino puntos de vista relativos ${ }^{45}$. Basta recordar la conversación entre Tirin y Bedap:

-Nunca se me había ocurrido pensar - dijo Tirin, imperturbable- en el hecho de que allá arriba, en Urras, hay gente sentada en una colina que mira a Anarres, que nos mira a nosotros, y dice: «Mira, ahí está la Luna». Para ellos nuestra Tierra es la Luna de ellos, y nuestra Luna es la Tierra.

-¿Dónde, entonces, está la verdad? -declamó Bedap, y bostezó.

-En la colina en que estás sentado -dijo Tirin (57-58, cap. II).

Esto puede valer sobre los sistemas sociales de Anarres y Urras, así como de los valores morales asociados con ellos. Cada uno representa una moral, cuya validez deniega la otra sociedad. Así, los 44 Burns, 119.

45 Según Scholes: «En [...] The Dispossessed, abordaría otro debatido tema, el choque de los sistemas sociopolíticos, representados por dos planetas vecinos, capitalista uno, socialista el otro. Según su autora, esta obra es una utopía ambigua, con lo que quiere decir que considera dos posibles caminos y examina con cierto detalle los costos y beneficios de ambos sistemas». Robert Scholes, La ciencia ficción: historia, ciencia y perspectiva (Madrid: Taurus, 1982) 93. 
habitantes de un país consideran que viven la utopía y miran a la otra sociedad como distópica:

For the Anarresti, of course, their own society is a utopia and that of A-Io on Urras a dystopia. But for the Urrasti, who have a different (indeed opposed) ethical and political values, the society of Anarres is a dystopia, whereas is their own society that is a $u^{2} \mathrm{pia}^{46}$.

Este afán relativista ha impulsado a Le Guin a mostrar tanto los puntos positivos como negativos de ambas sociedades; por eso, Anarres resuma aspectos utópicos y distópicos, pese a la declarada preferencia de la autora por el anarquismo. Bárbara Bucknall se soprende de que algunos de sus estudiantes, tras leer Los desposeídos, concluyan que Le Guin tiene, entre sus propósitos, promover la sociedad capitalista de Urras y demostrar que «one man's utopia was another man's dystopia» ${ }^{47}$.

A pesar de los esfuerzos antimaniqueos de Le Guin, es difícil percibir rasgos de utopía en Urras. Con todo, está claro que Anarres posee condiciones distópicas y utópicas al mismo tiempo. Ambos planetas, en tanto partes de un único sistema, son referentes éticos complementarios y existen como estructuras sociales contradictorias. En este sentido, se podría decir que constituyen un referente binario dialéctico. En tal relación, no son completos extremos de manera constante, sino que sostienen la ambigüedad de la vida humana y de los sistemas sociales.

46 Burns, 122.

47 Barbara J. Bucknall, Ursula K. Le Guin (Nueva York: Ungar, 1981) 103. 